\title{
Unmanned Aerial Systems Capabilities of the U.S. Geological Survey Woods Hole Coastal and Marine Science Center
}

Unmanned aerial system (UAS) technology provides a rapid and low-cost solution for mapping coastal environments and assessing short- and long-term changes. The interdisciplinary nature of the data collected and the breadth of applications make UAS technology applicable to multiple scientific investigations. The Aerial Imaging and Mapping (AIM) group at the U.S. Geological Survey (USGS) Woods Hole Coastal and Marine Science Center provides UAS services to scientists to advance the science mission of the Coastal-Marine Hazards and Resources Program. Scientists at the Woods Hole Coastal and Marine Science Center use UASs to acquire imagery of coastal and wetland environments, which is then used to produce detailed topographic and visual reflectance datasets. UAS technology supports the work of geologists, engineers, physical scientists, geographers, and geochemists who study coastal erosion, sediment transport, storm impacts, habitats, biomass, and marsh stability.

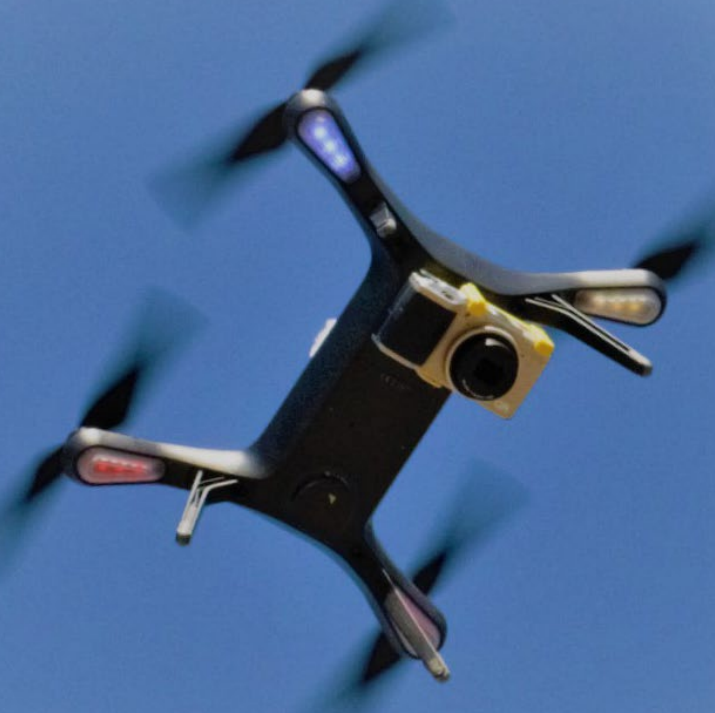

\section{Science Applications}

One of the primary science applications for UASs is mapping. The imagery collected by UASs, or drones, can make accurate maps by combining images, which can be interpolated into three-dimensional imagery with software that uses photogrammetric techniques to form orthomosaics and digital surface models. Using control points on the ground, these maps can be produced with horizontal resolutions of 5 to 10 centimeters (cm) and vertical precision within $8 \mathrm{~cm}$. Precision is determined by comparison with independent measurements from global navigation satellite system equipment with real-time kinematic positioning. The maps created with drone-acquired imagery are comparable in quality with images from light detection and ranging (lidar) surveys with color processing but can be produced at a fraction of the cost.

UAS map products can be used to meet many science objectives, including to quantify geomorphic changes in coastal landscapes, classify landcover and geomorphic features in wetland and riparian landscapes, and assess habitat suitability. UASs can be equipped with multispectral cameras (cameras that capture images within specific ranges across the electromagnetic spectrum) and can be used to classify vegetation or identify invasive species. Other potential applications for UASs include inferring nearshore bathymetry from imagery of waves, measuring shallow bathymetry in streams and estuaries, measuring stream or inlet flow using image processing methods or UAS-mounted radar, and making thermal imaging measurements to identify groundwater discharges. 


\section{UAS Capabilities}

The AIM group currently [2018] has five UAS pilots who are certified in accordance with Federal Aviation Agency and U.S. Department of the Interior (DOI) policies. The group currently has three 3DR Solo quadcopter drones and a Birds Eye View FireFly6 Pro fixed-wing UAS. Both UAS platforms can be mounted with a Ricoh GRII natural-color, high-resolution, global shutter digital camera, a MicaSense RedEdge3 multispectral wavelength camera, or a GoPro Hero 4 compact camera. Spectra Precision SP80 Global Navigation Satellite System receivers are used to precisely geolocate control points at survey areas. Images from drone flights are processed with commercial software (Agisoft Photoscan or Pix4D).

The AIM group can survey an area of approximately 0.5 to 1 square kilometer (160 acres) per day. Each multiplatform survey requires approximately five people to perform the survey efficiently, including two pilots, two survey crew, and a visual observer and data recorder.

The USGS Woods Hole Coastal and Marine Science Center maintains an ongoing collaboration with scientists and UAS technicians at the USGS National Unmanned Aircraft Systems Project in Denver, Colorado; other institutions, including the Woods Hole Oceanographic Institution; and local UAS operators and contractors. Woods Hole pilots have assisted the DOI Office of Aviation Services (OAS) in monitoring natural hazard emergencies and have been instructors for OAS-sponsored training classes. This networking and collaboration helps the AIM group remain current in a rapidly evolving technological field

\section{By Sandra Brosnahan and Chris Sherwood}

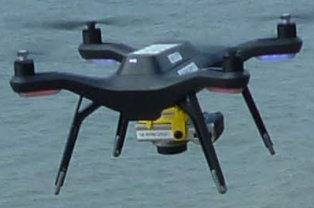

\section{For more information, contact}

Woods Hole Coastal and Marine Science Center Aerial Imaging and Mapping Group

U.S. Geological Survey

384 Woods Hole Road

Quissett Campus

Woods Hole, MA 02543

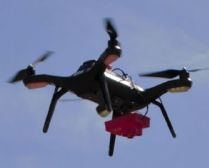

U.S. Geological Survey

Woods Hole Coastal and

Marine Science Center researchers Elizabeth Pendleton and Seth Ackerman flying a 3DR Solo quadcopter drone during a survey to image the ecosystem of a coastal marsh at Great Marsh in Barnstable, Massachusetts; by Sandra Brosnahan, U.S. Geological Survey

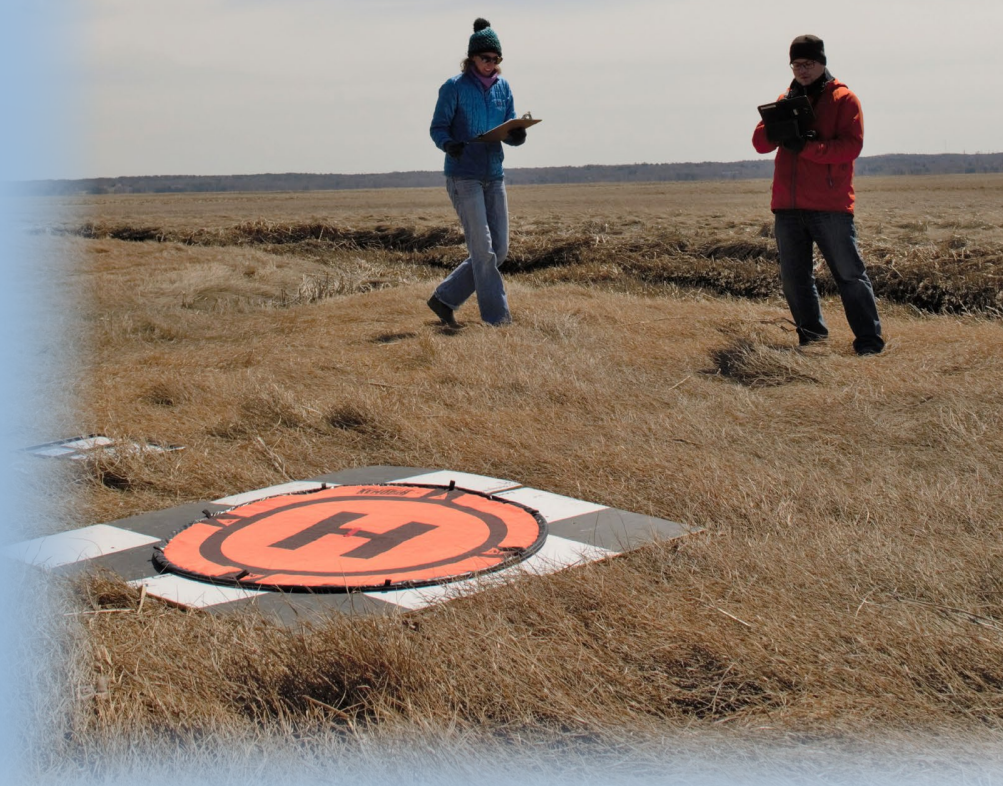

A 3DR Solo quadcopter drone flown by a certified pilot of the U.S. Geological Survey Woods Hole Coastal and Marine Science Center over Chimney Bluffs State Park in New York; by Chris Sherwood, U.S. Geological Survey. Data collected from this flight were used to map the face of a drumlin that is eroding into Lake Ontario.

https://www.usgs.gov/centers/whemse/science/aerial-imaging-and-mapping 